\title{
Gefitinib circumvents hypoxia-induced drug resistance by the modulation of HIF-1a
}

\author{
JIN KYUNG RHO ${ }^{1,3}$, YUN JUNG CHOI ${ }^{1}$, JIN KYUNG LEE ${ }^{2}$, BAEK-YEOL RYOO ${ }^{1}$, IM II NA ${ }^{1}$, \\ SUNG HYUN YANG ${ }^{1}$, CHEOL HYEON KIM $^{1}$, YOUNG DO YOO ${ }^{3}$ and JAE CHEOL LEE ${ }^{1}$ \\ Departments of ${ }^{1}$ Internal Medicine and ${ }^{2}$ Laboratory Medicine, Korea Cancer Center Hospital, \\ Korea Institute of Radiological and Medical Science, 215-4, Gongneung-dong, Nowon-gu, Seoul 139-706; \\ ${ }^{3}$ Graduate School of Medicine, Korea University College of Medicine, Korea University, Seoul 136-705, Korea
}

Received November 10, 2008; Accepted December 15, 2008

DOI: 10.3892/or_00000287

\begin{abstract}
Hypoxia-inducible factor $-1 \alpha(\mathrm{HIF}-1 \alpha)$ is a transcriptional factor which is activated by hypoxia and associated with cell survival, proliferation and drug resistance. Recent studies have shown that the down-stream molecules of the epidermal growth factor receptor (EGFR) signal are involved in the hypoxia-dependent or -independent HIF-1 $\alpha$ protein accumulation. Thus, we hypothesized that an EGFR-TK inhibitor, gefitinib, might circumvent the hypoxia-induced drug resistance via the regulation of HIF-1 $\alpha$ expression. In our data, treatment of gefitinib suppressed induced HIF- $1 \alpha$ by hypoxia. This action of gefitinib was caused by reduced protein stability without any change in the level of HIF-1 $\alpha$ mRNA. The effect of gefitinib on downregulation of HIF- $1 \alpha$ was reversed by transfection of constitutively active form of Akt. The cellular response to gefitinib was similar in both normoxia and hypoxia condition. However, the response to conventional chemotherapeutic drugs decreased $>50 \%$ under hypoxia condition and they did not change HIF-1 $\alpha$ expression. In addition, the suppression of HIF-1 $\alpha$ using siRNA overcame partially hypoxia-induced drug resistance. In conclusion, gefitinib was able to circumvent hypoxia-induced drug resistance suggesting that the effective suppression of HIF-1 $\alpha$ by the inhibition of EGFR-Akt pathway may overcome the hypoxia-induced drug resistance.
\end{abstract}

\section{Introduction}

Tissue hypoxia is an important phenomenon in developmental biology, normal physiology and many pathological conditions, such as, vascular, pulmonary diseases and solid tumors (1-4).

Correspondence to: Dr Jae Cheol Lee, Department of Internal Medicine, Korea Institute of Radiological and Medical Science, 215-4, Gongneung-dong, Nowon-gu, Seoul 139-706, Korea E-mail: jclee@kcch.re.kr

Key words: gefitinib, epidermal growth factor receptor, hypoxia, hypoxia-inducible factor- $1 \alpha$, lung cancer, resistance
It leads to acidic microenvironments that are low in oxygen and nutrients and can limit tumor growth and metastasis. However, hypoxic cells trigger a transcriptional program that can adapt to hypoxic microenvironment through alterations in cellular metabolism and the stimulation of neovascularization and sequent proliferation and survival $(5,6)$. Moreover, tumor hypoxia can result in more aggressive and metastatic phenotypes, associated with lower sensitivity to chemotherapy and radiotherapy and poor prognosis $(7,8)$. Thus, the suppression of factors that regulate hypoxic adaptation can enhance cancer therapy.

Hypoxia-inducible factor (HIF-1) is one of the key regulators of cellular adaptation to oxygen deprivation $(4,9)$. HIF-1 is a heterodimer composed of HIF- $1 \alpha$ and HIF-1及 subunits. HIF-1ß is constitutively expressed in normoxic cells, whereas HIF- $1 \alpha$ is degraded by the ubiquitin-proteasome pathway in normoxia and stabilized under hypoxia (10). Under normoxia, HIF-1 $\alpha$ is hydroxylated by specific prolyl hydroxylases, which is recognized by the von Hippel-Lindau (VHL) and it results in HIF-1 $\alpha$ degradation through the recognition component of the E3 ubiquitin-protein ligase. When oxygen tension is limited, the rates of proline hydroxylation is decreased and becomes stabilized.

Although oxygen tension plays a major role in the process of HIF-1 $\alpha$ stabilization and activation, previously, many studies showed that this response can be further modulated by major signal transduction pathways, including the ERK and PI3-K/ Akt cascades (11). These pathways are also associated with HIF-1 $\alpha$ activation in normoxia $(12,13)$. In addition, the induction of HIF- $1 \alpha$ in normoxia occurred by a variety of growth factors, such as EGF, IGF-1, IGF-2 and insulin (13-16), although the role of HIF-1 $\alpha$ in these conditions is unclear.

The epidermal growth factor receptor (EGFR) signaling pathway plays a key role in the regulation of cell proliferation, survival and differentiation $(17,18)$. It has been shown that the level of EGFR is up-regulated in many human tumor tissues including lung cancer (19). The activation of EGFR exerts cellular effects via ERK and PI3-K/Akt pathways. Thus, inhibition of EGFR signaling can lead to the reduction of induced-HIF-1 $\alpha$ by hypoxia and suppression of this pathway also may overcome HIF- $1 \alpha$-mediated resistance to chemo- 
therapeutic drugs. In this study, we examined whether gefitinib, an EGFR-TK inhibitor, might circumvent the hypoxia-induced drug resistance by the down-regulation of HIF-1 $\alpha$ expression in non-small cell lung cancer (NSCLC) cells. In addition, whether the suppression of HIF-1 $\alpha$ using siRNA can reverse hypoxia-induced drug resistance was investigated.

\section{Materials and methods}

Cell culture and reagents. Human NSCLC, A549 and H460 cells were grown in RPMI-1640 (Invitrogen, Carlsbad, CA) and Calu-1 cells were grown in MacCoy's 5A (Invitrogen). The media were supplemented with $10 \%$ fetal bovine serum (FBS), $100 \mathrm{U} / \mathrm{ml}$ penicillin and $100 \mu \mathrm{g} / \mathrm{ml}$ streptomycin (Invitrogen) at $37^{\circ} \mathrm{C}$ in atmosphere of $5 \% \mathrm{CO}_{2}$. LY294002, PD98059, MG132, cisplatin and paclitaxel were purchased from Sigma (St. Louis, MO). The gefitinib and gemcitabine were kindly provided by AstraZeneca Korea (Seoul, Korea) and Lilly Korea (Seoul, Korea), respectively.

Hypoxia treatment. Cells were plated in $60-\mathrm{mm}$ dishes, or 96-well plates according to the experiment requirements and cultured at $37^{\circ} \mathrm{C}$ in a $19 \% \mathrm{O}_{2}, 5 \% \mathrm{CO}_{2}$ previously. On the day of experiment, the medium was replaced with a fresh medium with $1 \%$ FBS. After treatment of indicated chemotherapeutic agents or inhibitors, cells were placed in a humidified airtight anaerobic incubator (Thermo Electron Corp., Waltham, MA) and set the incubator at $37^{\circ} \mathrm{C}, 1 \% \mathrm{O}_{2}$ and $5 \% \mathrm{CO}_{2}$.

MTT assay. Briefly, cells in the logarithmic growth phase were harvested and seeded in 96-well plates (Costar, Cambridge, MA, USA) overnight. The chemotherapeutic agents were added and cells were further incubated for $48 \mathrm{~h}$ under normoxia or hypoxia conditions. The viability of cells was determined using the MTT assay according to the method described by Carmichael et al (20).

Flow cytometric analysis. The cells were treated with chemotherapeutic agents or inhibitors and exposed to normoxia or hypoxia as indicated. Cells were harvested, washed with PBS containing $5 \mathrm{mM}$ EDTA and fixed in $70 \%$ ethanol at $-20^{\circ} \mathrm{C}$. After $24 \mathrm{~h}$, the cells were collected by centrifugation and resuspended in PBS containing $5 \mathrm{mM}$ EDTA. After digestion with $50 \mu \mathrm{g} / \mathrm{ml}$ RNase A, cells were stained with $50 \mu \mathrm{g} / \mathrm{ml}$ propidium iodide (PI) for at least $30 \mathrm{~min}$ before analysis using flow cytometry (Becton-Dickinson FACSort). The extent of cell death was determined by measuring the sub- $\mathrm{G}_{1}$ population.

Western blot analysis. Cells were washed with PBS and solubilized in lysis buffer (25 mM HEPES, 0.1\% SDS, $0.5 \%$ deoxycholate, $1 \%$ Triton X-100, $10 \mathrm{mM}$ EDTA, $10 \mathrm{mM} \mathrm{NaF}$ and $125 \mathrm{mM} \mathrm{NaCl}$ ). The protein was then collected after centrifugation at $10,000 \mathrm{x}$ g for $10 \mathrm{~min}$ at $4^{\circ} \mathrm{C}$. The resulting supernatant $(40 \mu \mathrm{g})$ was separated on $8-12 \%$ SDS-PAGE and transferred to nitrocellulose filters and probed with specific antibodies against HIF- $1 \alpha[(\mathrm{R} \& \mathrm{D}$ Systems, Minneapolis, MN), 1:1000], B-actin [AC-74 (Sigma), 1:4000], p-Akt [Ser 473 (Santa Cruz), 1:1000], Akt [C-20 (Santa Cruz), 1:2000],
p-Erk [E-4 (Santa Cruz), 1:1000], or Erk [K-23 (Santa Cruz), $1: 2000]$. The secondary antibodies used a horseradish peroxidase-conjugated antibodies diluted to 1:2000 and then the membrane were developed using an ECL kit (Amersham Biosciences, Piscataway, NJ).

Quantitative reverse transcription-PCR. Total RNA was isolated from cells according to the protocol of the Purescript RNA purification kit (Gentra Systems, Plymouth, MN). The cDNA was synthesized using Accupower RT mix reagent, according to the manufacturer's protocol (Bioneer Corp., Seoul, Korea). The reaction was incubated at $42^{\circ} \mathrm{C}$ for $60 \mathrm{~min}$ and then inactivated at $95^{\circ} \mathrm{C}$ for $5 \mathrm{~min}$. After inactivation, the cDNA was stored at $-20^{\circ} \mathrm{C}$ until use. RT-PCR was performed with the following cycling conditions: 30 cycles of $94^{\circ} \mathrm{C}$ for $45 \mathrm{sec}, 60-65^{\circ} \mathrm{C}$ for $45 \mathrm{sec}$ and $72^{\circ} \mathrm{C}$ for $1 \mathrm{~min}$ for $\beta$-actin and HIF- $1 \alpha$. This was followed by a final extension step at $72^{\circ} \mathrm{C}$ for $5 \mathrm{~min}$. The specific primer sequences were as follows: forward primer 5'-CTCAAAGTCGGACAGCCTCA-3' and reverse primer 5'-CCCTGCAGTAGGTTTCTGCT-3' for HIF- $1 \alpha$; forward primer 5'-GCGAGAAGATGATGACCCA GATC-3' and reverse primer 5'-CCAGTGGTACGGCCAG AGG-3' for B-actin. Amplified products $(3 \mu 1)$ were resolved on $5 \%$ polyacrylamide gels in TBE (90 mM Tris-Cl, $90 \mathrm{mM}$ boric acid, 1 mM EDTA), stained with ethidium bromide, visualized with a transilluminator and photographed. The level of gene expression was assessed by densitometric measurement of the amount of PCR products on scanned polyacrylamide gels. The units of expression were calculated as the ratio of the amount of PCR product of HIF- $1 \alpha$ mRNA to the amount of PCR product of the constitutively expressed housekeeping gene $\beta$-actin, the amount of which was assumed to be expressed constantly in the cell. The measurements were made with a Bio-Rad analysis system.

Transient transfection. pUSEamp(+)/Akt K179M and pUSEamp(+)/myr Akt were purchased by Upstate Biotechnology (Charlottesville, VA, USA). Transfections were performed using Lipofectamine 2000 (Invitrogen) according to the manufacturer's instructions. Cells were treated with or without indicated gefitinib after transfection and then were incubated in normoxia and hypoxia conditions. Cells were incubated for indicated time and Western blot analysis was conducted, as described above. Small interfering Silencer validated small interfering RNA (siRNA) for HIF-1 $\alpha$ was obtained from Santa Cruz. Transfection of siRNA was performed with Lipofectamine as described before. After transfection, cells were treated with anti-cancer drugs and incubated in normoxia and hypoxia conditions. Harvested cells conducted the flow cytometric analysis for determining cell death.

\section{Results}

Gefitinib inhibits the accumulation of HIF-1a under hypoxia by decreasing its stability. We investigated whether gefitinib could suppress the induction of HIF-1 $\alpha$ by hypoxia in A549 cells. As shown in Fig. 1A, the level of HIF-1 $\alpha$ peaked at $6 \mathrm{~h}$ in cells exposed to hypoxia, however gefitinib treatment effectively inhibited induction of HIF-1 $\alpha$ under hypoxia. This 
A

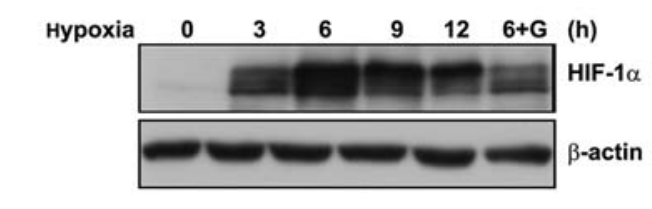

B

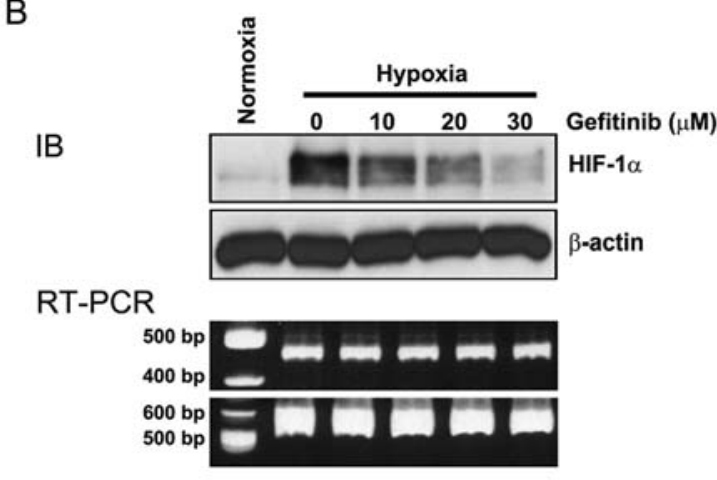

C

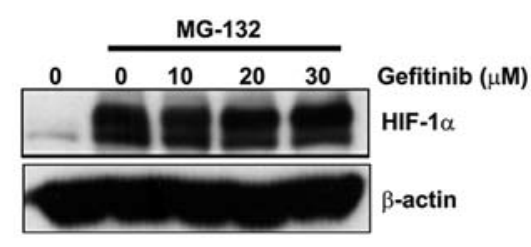

Figure 1. Gefitinib suppressed HIF-1 $\alpha$ under normoxia and hypoxia conditions. (A) A549 cells incubated for indicated times under hypoxia following a $3 \mathrm{~h}$ preincubation with or without $20 \mu \mathrm{M}$ gefitinib. HIF-1 $\alpha$ was analyzed by Western blotting. (B) Cells were treated with the indicated doses of gefitinib for $3 \mathrm{~h}$ and then incubated for $3 \mathrm{~h}$ under hypoxia. Cells were harvested and Western blotting and quantitative reverse transcription-PCR was done. (C) Cells were pretreated with $10 \mu \mathrm{M}$ MG132, proteasomal inhibitor. Six hours later, cells were treated with gefitinib for $3 \mathrm{~h}$ and Western blotting was done. G, gefitinib.

action of gefitinib was similar in other NSCLC cells, including H460 and Calu-1 (data not shown).

To determine the mechanism how gefitinib decreases induction of HIF-1 $\alpha$ under hypoxia, we observed the expression of HIF-1 $\alpha$ mRNA and protein stability. Although gefitinib suppressed HIF-1 $\alpha$ dose-dependently, the level of HIF-1 $\alpha$ mRNA did not change (Fig. 1B). However, gefitinib did not affect the expresson of HIF-1 $\alpha$, when MG-132, a proteasomal inhibitor was added before the treatment of gefitinib (Fig. 1C) suggesting that gefitinib exerts its effect on the modulation of HIF- $1 \alpha$ by decreasing the protein stability, not by affecting the protein synthesis.

The PI-3K/Akt pathway is involved in regulation of HIF-la by gefitinib. Gefitinib has been known that it can inhibit ERK1/2 and Akt signaling pathways effectively. Therefore, we examined how these pathways were related with the regulation of HIF-1 $\alpha$ by gefitinib. We used LY294002 and PD98059 as the specific inhibitor of PI-3K/Akt and ERK pathways, respectively. The inhibitory effect on hypoxia-
A

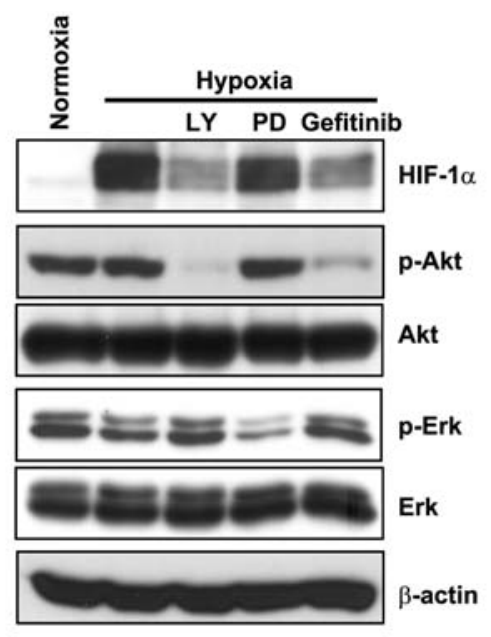

B

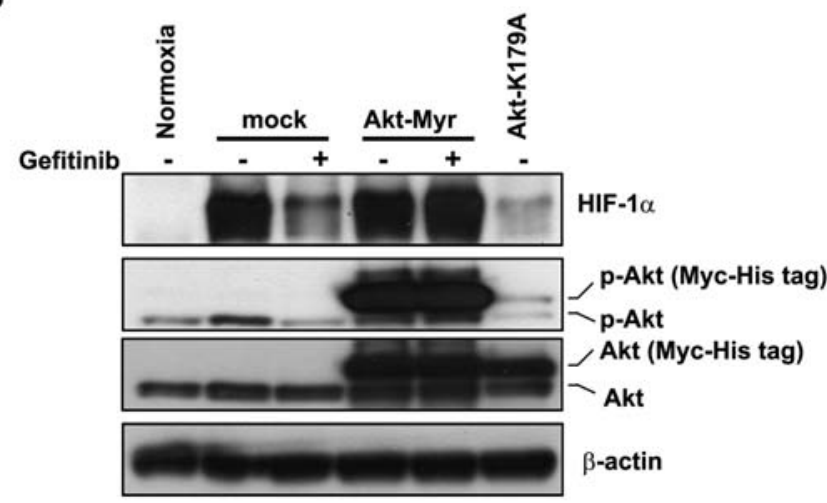

Figure 2. Hypoxia-induced HIF-1 $\alpha$ required the activation of Akt. (A) A549 cells were treated with indicated inhibitor (50 $\mu \mathrm{M} \mathrm{LY}, 20 \mu \mathrm{M} \mathrm{PD}, 20 \mu \mathrm{M}$ gefitinib) for $3 \mathrm{~h}$ and then exposed to hypoxia for $3 \mathrm{~h}$. (B) A549 cells were transfected by mock (control vector), Akt-Myr (constitutively active form), or Akt-K179A (dominant-negative form) and treated with or without $20 \mu \mathrm{M}$ gefitinib for $3 \mathrm{~h}$ before exposed to hypoxia for $3 \mathrm{~h}$. Harvested cells performed Western blotting.

induced HIF-1 $\alpha$ expression was only found when cells were treated with LY294002 suggesting that PI-3K/Akt pathway was involved in hypoxia-induced HIF-1 $\alpha$ (Fig. 2A). Supporting this, as shown in Fig. 2B, the suppression of HIF- $1 \alpha$ was not detected in cells transfected with constitutively active Akt. Moreover, inhibition of Akt using dominant-negative Akt blocked hypoxia-induced HIF-1 $\alpha$. Taken together, these results indicated that Akt pathway is required for hypoxia-induced HIF-1 $\alpha$ expression and suppression of HIF- $1 \alpha$ by gefitinib was mediated by inhibition of Akt pathway.

Gefitinib can overcome hypoxia-induced resistance. To assess the change of response to chemotherapeutic drugs by hypoxic environment in NSCLC cells, we used MTT assay and flow cytometry for determining growth-inhibitory effect and apoptosis. The cells were treated with chemotherapeutic drugs for $48 \mathrm{~h}$ under normoxia or hypoxia condition. The $\mathrm{IC}_{50}$ and $\mathrm{IC}_{80}$ values of chemotherapeutic drugs in NSCLC cells are shown in Table I. While the cells were more resistant to cisplatin, paclitaxel and gemcitabine in hypoxic condition, the response to gefitinib was similar in both normoxic and hypoxic conditions. The results of the flow cytometry were almost 
same to those of MTT assay (Fig. 3A) showing that hypoxia rendered cells to acquire the resistance to all tested chemotherapeutic drugs except gefitinib. Expectedly, these drugs did not lead to any change of HIF-1 $\alpha$ expression (Fig. 3B).

The suppression of HIF-la by the transfection of SiRNA enhances chemosensitivity under hypoxia. To verify that HIF-1 $\alpha$ is really important in hypoxia-induced drug resistance in NSCLC cells we observed the sensitivity to chemotherapeutic drugs after the transfection of HIF-1 $\alpha$ siRNA. The level of HIF- $1 \alpha$ mRNA was reduced by $\sim 60 \%$ compared to that of cells treated with control siRNA in hypoxia (data not shown). Under identical conditions, Western blot analysis showed that HIF-1 $\alpha$ protein was detected at all time within the studied time period from 3 to $48 \mathrm{~h}$ of hypoxic treatment in cells treated with control siRNA; however, HIF- $1 \alpha$ was markedly reduced at early time (from 3 to $6 \mathrm{~h}$ ) and disappeared at $12 \mathrm{~h}$ in cells treated with HIF- $1 \alpha$-siRNA (Fig. 4A). The suppression of HIF- $1 \alpha$ by the HIF- $1 \alpha$ siRNA led to partially overcome the hypoxia-induced drug resistance. The proportion of sub- $\mathrm{G}_{1}$ in flow cytometry increased from 22 to $30 \%$ with cisplatin, 16 to $29 \%$ with paclitaxel and 28 to $37 \%$ with gemcitabine (Fig. 4B). Although the response was not fully recovered as in normoxia, these findings indicate that the inhibition of HIF- $1 \alpha$ can lead to circumvent hypoxiainduced resistance in NSCLC.

\section{Discussion}

The EGFR overexpression was frequently found in nonsmall cell lung cancer and associated with poor prognosis $(21,22)$. Previously, many studies have reported the role of EGFR signaling in HIF-1 $\alpha$ stabilization and activation under normoxia and hypoxia condition $(11,14,23,24)$, although the expression of HIF-1 $\alpha$ under hypoxia condition is regulated mainly by ubiquitination and proteasomal degradation (10). We found that the treatment with EGF increased HIF-1 $\alpha$ expression under normoxia condition (data not shown). Both EGF- and hypoxia-induced HIF-1 $\alpha$ expression was reduced by the treatment with gefitinib suggesting that the control of HIF-1 $1 \alpha$, regardless of its induction mechanisms, could be achievable through the inactivation of EGFR signaling.

The action of gefitinib within cell masks ATP binding site of EGFR tyrosine kinase and, in consequence, it blocks effectively ERK and PI-3/Akt pathway $(25,26)$. In our data, hypoxia-induced HIF-1 $\alpha$ was repressed by the genetic and chemical inhibition of the PI-3/Akt pathway, but not by the inhibition of MAPK pathway. In addition, the ability of geifitnib to reduce HIF-1 $\alpha$ expression was compensated by the restoration of a constitutively active Akt. These results indicate that hypoxia-induced HIF-1 $\alpha$ expression requires the activation of Akt and inhibition of HIF-1 $\alpha$ expression by gefitinib result from the block of Akt activity among the EGFR signaling pathways. Consistent with our data, many studies have showed that induction of HIF-1 $\alpha$ under hypoxia is dependent on a PI-3/Akt pathway $(14,27,28)$; however, the mechanisms of HIF-1 $\alpha$ regulation via Akt remain unclear. Some studies suggested that Akt pathway induced HIF-1 $\alpha$ stabilization (29) 
A

Control
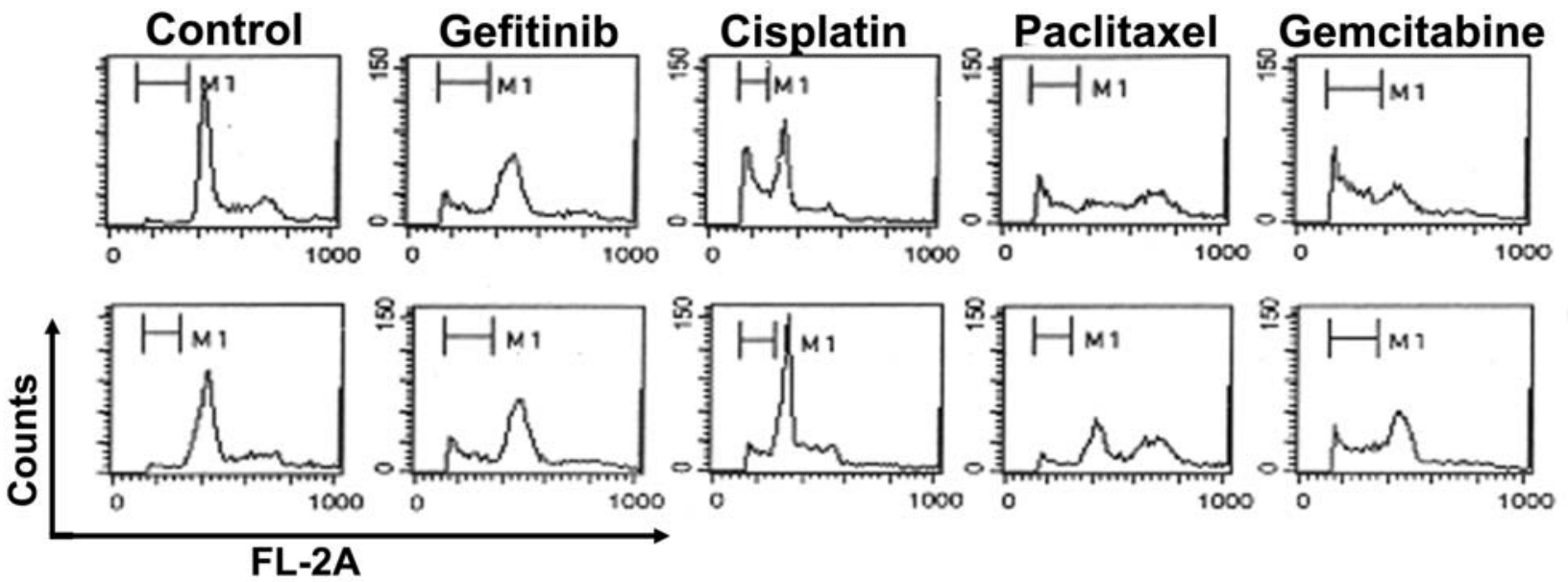

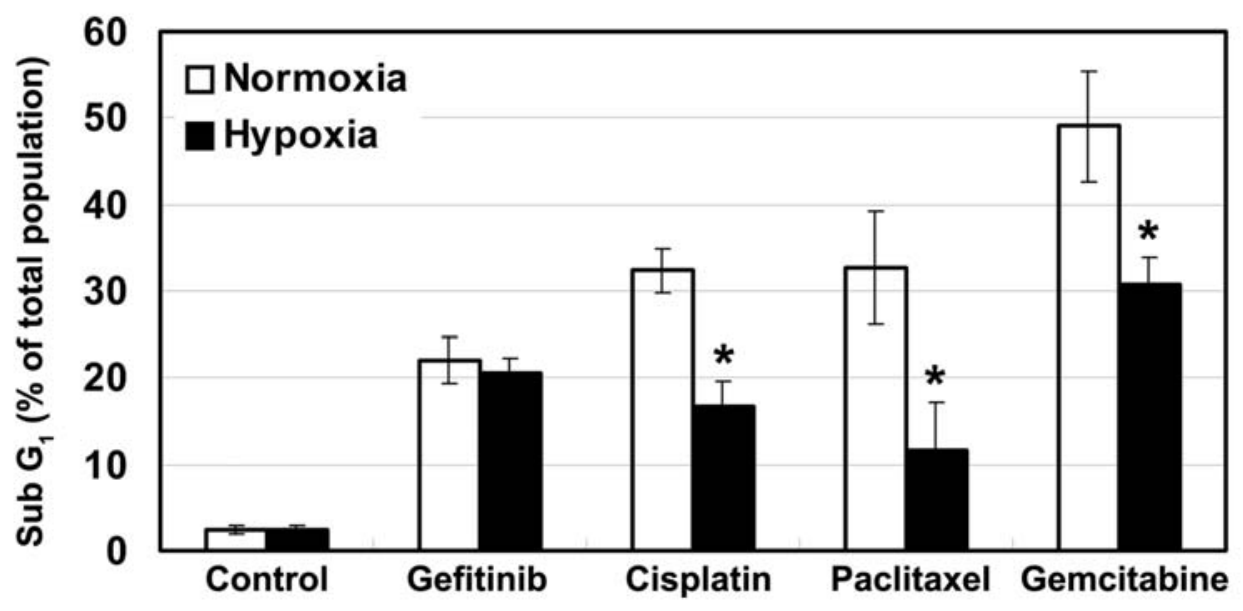

B

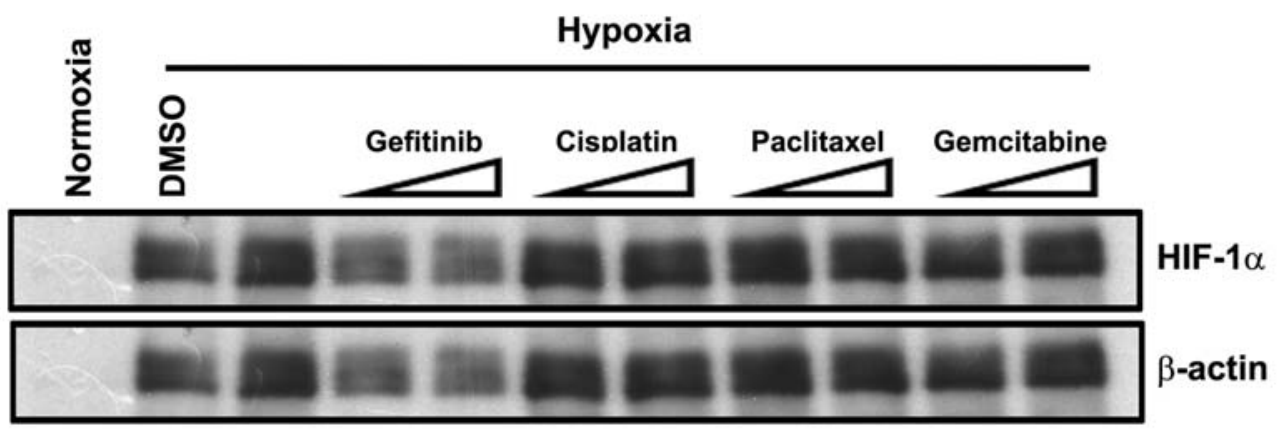

Figure 3. Drug-induced cell death under normoxia and hypoxia condition in A549 cells. (A) A549 cells were treated with or without the indicated drug of $\mathrm{IC}_{80}$ values (15 $\mu \mathrm{M}$ gefitinib, $35 \mu \mathrm{M}$ cisplatin, $120 \mu \mathrm{M}$ gemcitabine and $3 \mu \mathrm{M}$ paclitaxel) for $48 \mathrm{~h}$ under normoxia or hypoxia condition. Cells were harvested, stained with propidium iodide (PI) and analyzed by flow cytometry. Diagrams of PI flow cytometry in a representative experiment are presented above the graphs. Cell death was determined from three experiments and the bars represent SD. (B) Cells were treated with the indicated drug (gefitinib, 10 and $20 \mu \mathrm{M}$; cisplatin, 25 and $35 \mu \mathrm{M}$; paclitaxel, 1 and $3 \mu \mathrm{M}$; gemcitabine, 100 and $150 \mu \mathrm{M}$ ) or control solvent (DMSO) for 3 h before incubation under hypoxia conditions for $3 \mathrm{~h}$. Cell lysates were blotted with HIF-1 $\alpha$ antibodies. P-values were calculated to assess the difference of drug-response according to the hypoxia condition. ${ }^{*} \mathrm{P}<0.05$.

and enhanced the translation $(30,31)$. Supporting this, the modulation of HIF- $1 \alpha$ by gefitinib was mediated by degradation through proteasomal pathway in our study. Together, we believe that gefitinib modulates HIF- $1 \alpha$ expression by the inhibition of Akt affecting the HIF-1 $\alpha$ protein stability.

HIF-1 $\alpha$ plays an important role in modulating the response to chemotherapeutic drugs $(7,32,33)$. Indeed, several studies 
A

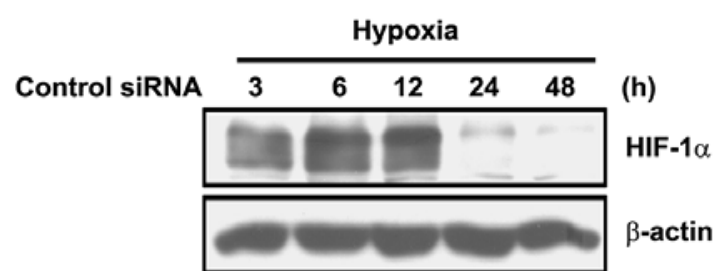

HIF-1 $\alpha$ siRNA

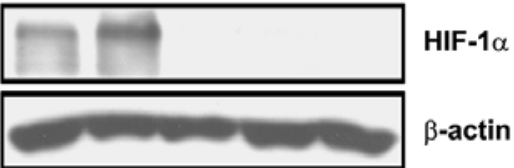

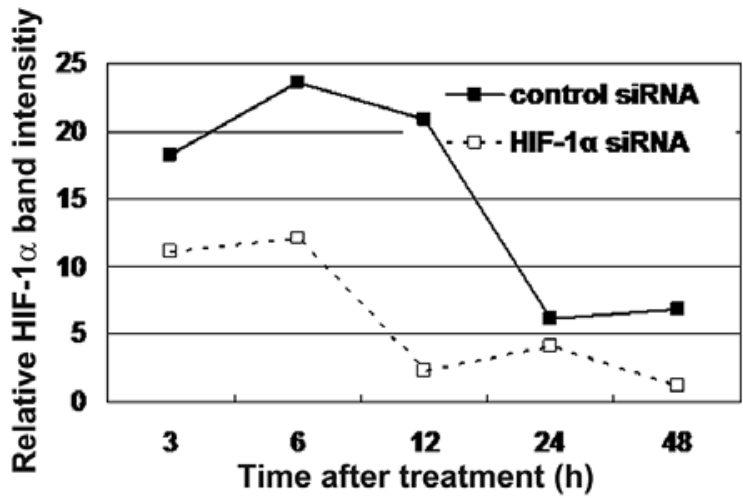

Time after treatment (h)

B

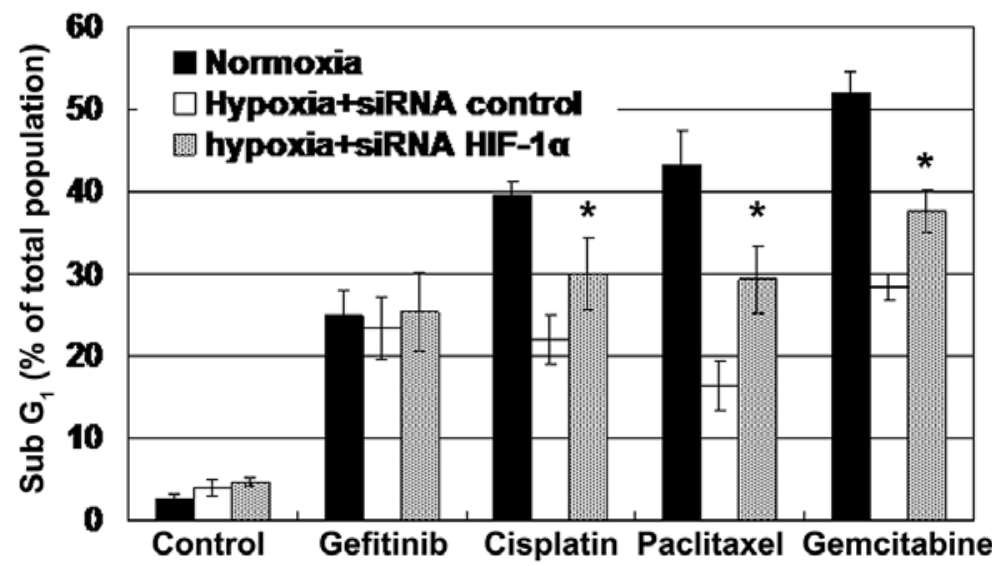

Figure 4. The suppression of HIF-1 $\alpha$ by siRNA enhanced chemosensitivity under hypoxia. (A) A549 cells were transfected by control siRNA (100 nM) or HIF-1 $\alpha$ siRNA $(100 \mathrm{nM})$ and cultured for $24 \mathrm{~h}$ under normoxia condition. After transfection, cells cultured for the given time periods under hypoxia conditions. HIF-1 $\alpha$ was analyzed by Western blotting. The graph shows the densitomeric quantification of HIF-1 $\alpha$ Western blot analysis. (B) Cells were transfected with control siRNA or HIF-1 $\alpha$ siRNA for $24 \mathrm{~h}$ and then treated with or without the indicated drug (15 $\mu \mathrm{M}$ gefitinib, $35 \mu \mathrm{M}$ cisplatin, $120 \mu \mathrm{M}$ gemcitabine and $3 \mu \mathrm{M}$ paclitaxel) for $48 \mathrm{~h}$ under normoxia or hypoxia conditions. Cells were harvested, stained with propidium iodide (PI) and analyzed by flow cytometry. Cell death was determined from three experiments and the bars represent SD. P-values were calculated to assess the difference of drug-response according to the suppression of HIF- $1 \alpha .{ }^{*} \mathrm{P}<0.05$.

showed that the elevated level of HIF-1 $\alpha$ was correlated with radio-resistance and chemo-resistance (32,34-36), which was associated with poor prognosis $(37,38)$. Therefore, HIF- $1 \alpha$ targeted therapy is potential for enhancement of therapeutic efficacy in many tumor cells. In our study, we showed that the response to conventional chemotherapeutic drugs in NSCLC cells was significantly decreased under hypoxic condition and the down-regulation of HIF-1 $\alpha$ by the transfection of siRNA could cause to partially restore the drug sensitivity supporting the role of HIF- $1 \alpha$ on the therapeutic resistance. We hypothesized that gefitinib could circumvent hypoxia-induced drug resistance considering that the EGFR signal pathway is related with the HIF-1a expression and gefitinib can effectively control it. As expected, we found that HIF-1 $\alpha$ was suppressed by gefitinib and the response to gefitinib was similar both in hypoxic and normoxic conditions.

It is still unclear whether the down-regulation of HIF-1 $\alpha$ is the key factor rendering gefitinib to circumvent hypoxiainduced chemoresistance as EGFR signal-related effectors also can be involved in the response to drugs. Indeed, some studies have demonstrated that hypoxic conditions can activate down-stream proteins (Akt and Erk) of the EGFR pathway and activation of these proteins are associated with chemo-resistance $(39,40)$. Nevertheless, we believe that the capability of gefitinib to overcome hypoxia-induced drug resistance is dependent on the regulation of HIF-1 $\alpha$ expression, based on previous studies and the results of this study showing the relationship between HIF- $1 \alpha$ and drug response.

In summary, we showed that gefitinib inhibited hypoxia-induced HIF-1 $\alpha$ expression via modulation of Akt in NSCLC cells and could circumvent hypoxia-induced drug resistance suggesting the EGFR inhibitors might be useful to overcome HIF-1 $\alpha$-related problems in cancer treatment.

\section{Acknowledgements}

We thank Sun Ah Park for expert technical assistance. 


\section{References}

1. Minet E, Michel G, Remacle J and Michiels C: Role of HIF-1 as a transcription factor involved in embryonic development cancer progression and apoptosis (review). Int J Mol Med 5: 253-259, 2000

2. Semenza GL: Hypoxia-inducible factor 1: Master regulator of O2 homeostasis. Curr Opin Genet Dev 8: 588-594, 1998.

3. Greenlee RT, Murray T, Bolden S and Wingo PA: Cancer statistics, 2000. CA Cancer J Clin 50: 7-33, 2000

4. Ryan HE, Poloni M, McNulty W, Elson D, Gassmann M, Arbeit JM and Johnson RS: Hypoxia-inducible factor-1alpha is a positive factor in solid tumor growth. Cancer Res 60: 4010-4015 2000 .

5. Harris AL: Hypoxia - a key regulatory factor in tumour growth. Nat Rev Cancer 2: 38-47, 2002.

6. Pugh CW and Ratcliffe PJ: Regulation of angiogenesis by hypoxia: Role of the HIF system. Nat Med 9: 677-684, 2003.

7. Unruh A, Ressel A, Mohamed HG, et al: The hypoxia-inducible factor- 1 alpha is a negative factor for tumor therapy. Oncogene 22: 3213-3220, 2003.

8. Le QT, Denko NC and Giaccia AJ: Hypoxic gene expression and metastasis. Cancer Metastasis Rev 23: 293-310, 2004.

9. Hockel M, Schlenger K, Hockel S and Vaupel P: Hypoxic cervical cancers with low apoptotic index are highly aggressive. Cancer Res 59: 4525-4528, 1999.

10. Maxwell PH, Wiesener MS, Chang GW, et al: The tumour suppressor protein VHL targets hypoxia-inducible factors for oxygen-dependent proteolysis. Nature 399: 271-275, 1999.

11. Semenza GL: Targeting HIF-1 for cancer therapy. Nat Rev Cancer 3: 721-732, 2003.

12. Phillips RJ, Mestas J, Gharaee-Kermani M, et al: Epidermal growth factor and hypoxia-induced expression of CXC chemokine receptor 4 on non-small cell lung cancer cells is regulated by the phosphatidylinositol 3-kinase/PTEN/AKT/ mammalian target of rapamycin signaling pathway and activation of hypoxia inducible factor-1alpha. J Biol Chem 280: 22473-22481, 2005 .

13. Laughner E, Taghavi P, Chiles K, Mahon PC and Semenza GL: HER2 (neu) signaling increases the rate of hypoxia-inducible factor 1alpha (HIF-1alpha) synthesis: Novel mechanism for HIF-1-mediated vascular endothelial growth factor expression. Mol Cell Biol 21: 3995-4004, 2001.

14. Zhong H, Chiles K, Feldser D, et al: Modulation of hypoxiainducible factor 1alpha expression by the epidermal growth factor/phosphatidylinositol 3-kinase/PTEN/AKT/FRAP pathway in human prostate cancer cells: Implications for tumor angiogenesis and therapeutics. Cancer Res 60: 1541-1545, 2000.

15. Fukuda R, Hirota K, Fan F, Jung YD, Ellish LM and Semenza GL: Insulin-like growth factor 1 induces hypoxia-inducible factor 1mediated vascular endothelial growth factor expression, which is dependent on MAP kinase and phosphatidylinositol 3-kinase signaling in colon cancer cells. J Biol Chem 277: 38205-38211, 2002.

16. Feldser D, Agani F, Iyer NV, Pak B, Ferreira G and Semenza GL: Reciprocal positive regulation of hypoxia-inducible factor 1alpha and insulin-like growth factor 2. Cancer Res 59: 3915-3918, 1999.

17. Danielsen AJ and Maihle NJ: The EGF/ErbB receptor family and apoptosis. Growth Factors 20: 1-15, 2002.

18. Chrysogelos SA and Dickson RB: EGF receptor expression, regulation, and function in breast cancer. Breast Cancer Res Treat 29: 29-40, 1994.

19. Scagliotti GV, Selvaggi G, Novello S and Hirsch FR: The biology of epidermal growth factor receptor in lung cancer. Clin Cancer Res 10: 4227s-4232s, 2004

20. Carmichael J, DeGraff WG, Gazdar AF, Minna JD and Mitchell JB: Evaluation of a tetrazolium-based semiautomated colorimetric assay: Assessment of radiosensitivity. Cancer Res 47: 943-946, 1987

21. Selvaggi G, Novello $\mathrm{S}$, Torri $\mathrm{V}$, et al: Epidermal growth factor receptor overexpression correlates with a poor prognosis in completely resected non-small-cell lung cancer. Ann Oncol 15: 28-32, 2004.
22. Hirsch FR, Varella-Garcia M, Bunn PA Jr, et al: Epidermal growth factor receptor in non-small-cell lung carcinomas: Correlation between gene copy number and protein expression and impact on prognosis. J Clin Oncol 21: 3798-3807, 2003.

23. Jiang BH, Jiang G, Zheng JZ, Lu Z, Hunter T and Vogt PK: Phosphatidylinositol 3-kinase signaling controls levels of hypoxia-inducible factor 1. Cell Growth Differ 12: 363-369, 2001.

24. Dery MA, Michaud MD and Richard DE: Hypoxia-inducible factor 1: Regulation by hypoxic and non-hypoxic activators. Int J Biochem Cell Biol 37: 535-540, 2005.

25. Ono M, Hirata A, Kometani T, et al: Sensitivity to gefitinib (iressa, ZD1839) in non-small cell lung cancer cell lines correlates with dependence on the epidermal growth factor (EGF) receptor/extracellular signal-regulated kinase 1/2 and EGF receptor/Akt pathway for proliferation. Mol Cancer Ther 3: 465-472, 2004

26. Raben D, Helfrich B, Ciardiello F and Bunn PA: Understanding the mechanisms of action of EGFR inhibitors in NSCLC: What we know and what we do not know. Lung Cancer 41: S15-S22, 2003.

27. Mazure NM, Chen EY, Laderoute KR and Giaccia AJ: Induction of vascular endothelial growth factor by hypoxia is modulated by a phosphatidylinositol 3-kinase/Akt signaling pathway in ha-ras-transformed cells through a hypoxia inducible factor-1 transcriptional element. Blood 90: 3322-3331, 1997.

28. Zundel W, Schindler C, Haas-Kogan D, et al: Loss of PTEN facilitates HIF-1-mediated gene expression. Genes Dev 14: 391-396, 2000

29. Flugel D, Gorlach A, Michiels C and Kietzmann T: Glycogen synthase kinase 3 phosphorylates hypoxia-inducible factor 1 alpha and mediates its destabilization in destabilization in a VHL-independent manner. Mol Cell Biol 27: 3253-3265, 2007.

30. Sonenberg N and Gingras AC: The mRNA 5' cap-binding protein eIF4E and control of cell growth. Curr Opin Cell Biol 10: 268-275, 1998 .

31. Takata M, Ogawa W, Kitamura T, et al: Requirement for akt (protein kinase B) in insulin-induced activation of glycogen synthase and phosphorylation of 4E-BP1 (PHAS-1). J Biol Chem 274: 20611-20618, 1999

32. Erler JT, Cawthorne CJ, Williams KJ, et al: Hypoxia-mediated down-regulation of bid and bax in tumors occurs via hypoxiainducible factor 1-dependent and -independent mechanisms and contributes to drug resistance. Mol Cell Biol 24: 2875-2889, 2004.

33. Yeo EJ, Chun YS, Cho YS, et al: YC-1: A potential anticancer drug targeting hypoxia-inducible factor 1. J Natl Cancer Inst 95: $516-525,2003$.

34. Sasabe E, Tatemoto Y, Li D, Yamamoto T and Osaki T: Mechanism of HIF-1alpha-dependent suppression of hypoxiainduced apoptosis in squamous cell carcinoma cells. Cancer Sci 96: 394-402, 2005 .

35. Bos R, Zhong H, Hanrahan CF, et al: Levels of hypoxia-inducible factor-1 alpha during breast carcinogenesis. J Natl Cancer Inst 93: 309-314, 2001 .

36. Bachtiary B, Schindl M, Potter R, et al: Overexpression of hypoxia-inducible factor 1alpha indicates diminished response to radiotherapy and unfavorable prognosis in patients receiving radical radiotherapy for cervical cancer. Clin Cancer Res 9: 2234-2240, 2003.

37. Schindl M, Schoppmann SF, Samonigg H, et al: Overexpression of hypoxia-inducible factor 1 alpha is associated with an unfavorable prognosis in lymph node-positive breast cancer. Clin Cancer Res 8: 1831-1837, 2002.

38. Aebersold DM, Burri P, Beer KT, et al: Expression of hypoxiainducible factor-1alpha: A novel predictive and prognostic parameter in the radiotherapy of oropharyngeal cancer. Cancer Res 61: 2911-2916, 2001.

39. Kwon DS, Kwon CH, Kim JH, Woo JS, Jung JS and Kim YK: Signal transduction of MEK/ERK and PI3K/Akt activation by hypoxia/reoxygenation in renal epithelial cells. Eur J Cell Biol 85: 1189-1199, 2006

40. Lee SM, Lee CT, Kim YW, Han SK, Shim YS and Yoo CG: Hypoxia confers protection against apoptosis via PI3K/Akt and ERK pathways in lung cancer cells. Cancer Lett 242: 231-238, 2006. 